\title{
MEMÓRIA URBANA E ESQUECIMENTOS PAULISTANOS
}

\author{
DEPOIS DE PASSAR DUZENTOS ANOS SONHANDO \\ COM O PRÓPRIO FUTURO, AS GRANDES CIDADES \\ RECENTEMENTE ACORDARAM PARA A VALORIZAÇÃO \\ DE SEU PASSADO. SÃO PAULO TAMBÉM ACORDOU, \\ EMBORA AINDA ESTEJA COM O RACIOCÍNIO LENTO E \\ A VISTA TURVA
}

I POR MARTIN JAYO

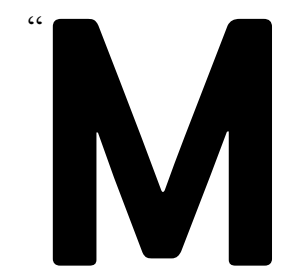

emória, s.f." costuma ser definida pelos dicionários como a capacidade ou faculdade de reter informações, ideias ou acontecimentos passados. Nesse sentido mais usual, ela é uma qualidade que diz respeito a indivíduos. Mas não é dessa memória, objeto de estudo de neurocientistas e psicólogos, que queremos nos ocupar aqui.

Para além dos indivíduos, também existem formas de memória cultural ou coletiva que passaram a ser estudadas, sobretudo, a partir da obra do sociólogo francês Maurice Halbwachs (1877-1945). Uma das variantes dessas formas é aquela que diversos autores - entre eles, o geógrafo brasileiro Maurício de Almeida Abreu (1948-2011) - chamam de memória urbana, ou memória das cidades.

Diferentemente da individual, que pode prescindir de um suporte no mundo físico (na medida em que se constitui de lembranças ou reminiscências - conscientes ou não que habitam a mente das pessoas), a memória das cidades pressupõe uma base material.É uma memória palpável, constituída por um estoque de vestígios físicos do passado que, reapropriados no presente, permitem-nos estabelecer uma relação identitária com o território. Daí a importância de atitudes e políticas voltadas à preservação das edificações e demais bens presentes nas paisagens das cidades que possam ser considerados elementos repositórios de memória.

\section{O PASSADO COMO NOVIDADE}

A preocupação com esse patrimônio é uma atitude muito recente nas grandes cidades. Regra geral, os principais centros urbanos do mundo cresceram ao longo dos últimos séculos com pouca ou nenhuma preocupação com sua memória, e só nas últimas duas ou três décadas começaram a desenvolver um discurso de valorização do passado.

No livro História e memória, escrito em 1988, o historiador francês Jacques Le Goff oferece uma explicação para esse fenômeno. Para o autor, o final do século XX encerrou uma era de otimismo e fé no futuro, 

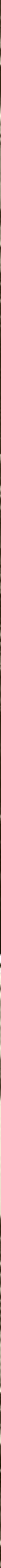
inaugurada duzentos anos antes pelo Iluminismo. O espírito iluminista fundou uma forte crença no progresso da humanidade, que influenciaria o pensamento ocidental durante todo o século XIX e boa parte do XX. Nessa visão de mundo, reverenciar o passado, considerando-o parte de nossa identidade, era uma atitude desestimulada.O futuro era sempre mais brilhante, e o antigo era sinônimo de superado, ultrapassado.

No século XX, uma série de acontecimentos traumáticos jogou um balde de água fria na concepção iluminista de progresso. Duas guerras mundiais, o holocausto, a bomba atômica, a guerra fria e a resultante consciência da capacidade de autodestruição da espécie humana minaram a fé ilimitada no progresso e sugeriram que, ao contrário do que se vinha pensando há duzentos anos, a humanidade não caminhava necessariamente para dias melhores e gloriosos. Isso alterou a forma como olhamos para o passado: valorizá-lo deixou de ser reacionário.

Foi em plena vigência desse paradigma de fé no futuro e valorização do novo que a maior parte das grandes cidades se desenvolveu, e isso explicaria, ao menos em parte, $o$ pouco apego à memória urbana tradicionalmente demonstrado por elas. A desilusão do século XX tem feito florescer um novo discurso de apreciação do passado, comum às mais diversas cidades, ainda que em muitos casos seja pouco o que sobrou de substantivo para ser valorizado.

\section{A MEMÓRIA DE SÃO PAULO}

São Paulo, ao menos entre as cidades brasileiras, foi a que encarnou com mais intensidade a ideologia do progresso. Apesar dos quase 460 anos de história de seu núcleo central, fundado em 1554, ela praticamente não apresenta, na paisagem construída, vestígios anteriores à década de 1930.

Do aglomerado pacato que era até o fim do século XIX, a cidade foi rapidamente promovida à metrópole de importância mundial e firmou uma imagem laboriosa, dinâmica e progressista no século XX. Sem preocupações de preservação, recebeu diferentes planos e intervenções urbanísticas (dos projetos de ajardinamento afrancesados de Joseph Bouvard, em 1910, ao minhocão de Paulo Maluf, em 1969, passando pelo plano de avenidas de Francisco Prestes Maia entre as décadas de 1930 e 1950), e enfrentou um processo de desenvolvimento urbano baseado em ataques sistemáticos ao seu estoque de memória material.

Nesse processo, foi demolida e reconstruída sucessivas vezes (como mostra o arquiteto Benedito Lima de Toledo em seu livro São Paulo: três cidades em um século), tornando-se uma cidade que não permite às novas gerações reconhecer os locais onde viveram seus avós, ou mesmo seus pais. Essa agressão à paisagem - constantemente construída e reconstruída - não se fez veladamente, mas, ao contrário, era um bem-visto indício de arrojo urbano e modernidade. Entre muitos exemplos disso cabe um destaque especial às publicações comemorativas do Quarto Centenário da cidade, patrocinadas pela Prefeitura em 1954. Em uma delas, um luxuoso livro intitulado Eis São Paulo, publicado em cinco idiomas e organizado com a colaboração do poeta Guilherme de Almeida, São Paulo aparece festejada como a cidade onde "a cada meia hora nasce uma nova casa, e as velhas desaparecem de um dia para outro".

\section{ACORDAR SONOLENTO}

Mas como dissemos, o século XX acabou e as grandes cidades começaram a despertar de seus sonhos de progresso. Deixaram de crer em um futuro glorioso e começaram, ainda que em alguns casos tardiamente, a buscar preservar sua memória.

No caso de São Paulo, não é difícil notar o crescimento recente de discursos que pregam o resgate e a valorização do antigo, assumindo proporções inéditas na história da cidade. As pressões da sociedade civil em torno do destino do cinema Belas Artes, que resultaram no tombamento parcial do prédio em dezembro de 2012, podem ser consideradas um entre tantos exemplos do fenômeno. Embora o resultado prático desse tombamento ainda não esteja claro, uma vez que o prédio permanece sem uso e deteriorando-se, o evento mostra a importância que a sociedade vem dando ao tema da preservação.

\section{ESQUECIMENTOS PAULISTANOS}

Mas se por um lado é possível dizer que São Paulo parece ter acordado para uma maior preocupação com a conservação dos seus bens de memória, por outro ainda é preciso vencer aquela fase de torpor que normalmente se segue a longos períodos de sono. Recém-despertada, a cidade parece estar ainda com a vista turva, o raciocínio lento e a voz rouca para construir de forma convincente atitudes e políticas de proteção à sua memória.

Os três pequenos casos recentes relatados a seguir, selecionados entre muitos possíveis, ilustram a maneira contraditória e desfocada como a cidade tem desenvolvido seu discurso de valorização da memória. Esperemos que, com o tempo, esse discurso amadureça. Por ora, cabe a nós refletir sobre os equívocos e tentar aprender com eles. 


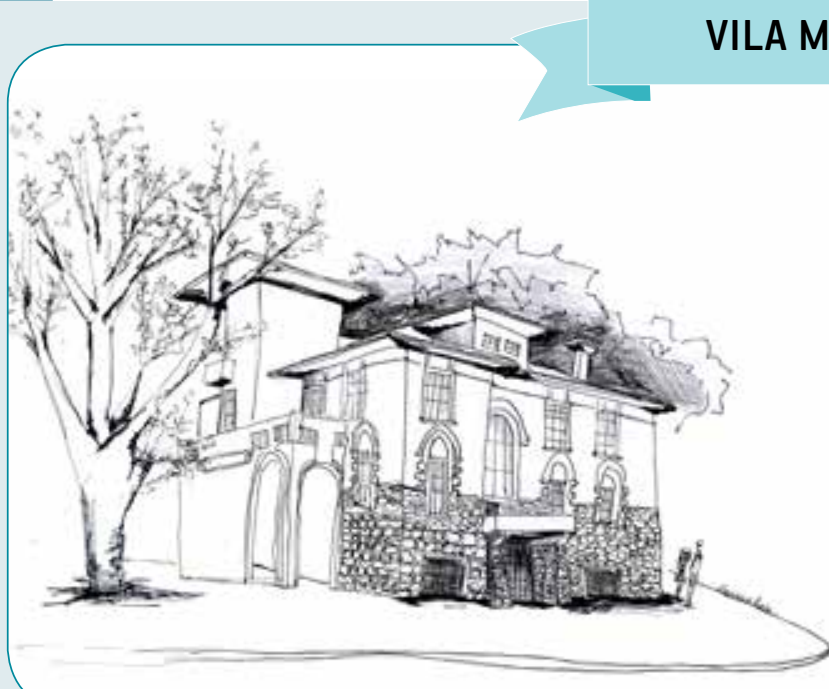

Não é difícil, para quem viveu em São Paulo até 2005, lembrar-se de um imponente palácio em estilo florentino — ocupado por um restaurante, em seus últimos anos - que se localizava na esquina das ruas Vergueiro e Carlos Petit. Por situar-se em local de grande visibilidade e fluxo constante de tráfego, ele era uma importante referência visual. Também possuía um significado histórico muito forte, por ter sido casa da família Petit, pioneira na ocupação da Vila Mariana no início do século XX.

A construção foi demolida e, em seu lugar, instalou-se um condomínio residencial. Apesar de não ter sobrado qualquer vestígio da antiga casa, chama a atenção a forma como o marketing do empreendimento reconheceu a importância do bem que foi destruído: "More onde um dia foi o berço da Vila Mariana", e "Não existe nada mais gratificante do que morar em um local que tem história", dizem as peças publicitárias do empreendimento, que, paradoxalmente, são o único registro de memória que restou do local.

\section{CAMBUCI}

Houve um tempo em que certos bairros de São Paulo eram repletos de fábricas, e algumas eram assinadas pelos maiores nomes da arquitetura brasileira, como a projetada por Rino Levi (1901-1965) para a Companhia Jardim de Cafés Finos. O prédio, de significativo valor arquitetônico e histórico, levantado em 1942, ficava no bairro do Cambuci.

O edifício foi demolido em 2012 para a construção de um condomínio residencial. Além da perda de uma edificação marcante na memória local, também chama a atenção o nome escolhido para o empreendimento: "Innova Cambuci". Algumas cidades, como Barcelona, têm conseguido preservar sua antiga arquitetura industrial, requalificando-a para novos usos. Já em São Paulo, o empreendimento optou por “innovar". E o fez com dois "n", respeitando uma grafia vigente no passado. $\mathrm{O}$ antigo também é enaltecido no website do empreendimento, que é ilustrado com imagens de prédios históricos da cidade: 0

Teatro Municipal, a Catedral da Sé, o edifício Altino Arantes e o Museu do lpiranga.

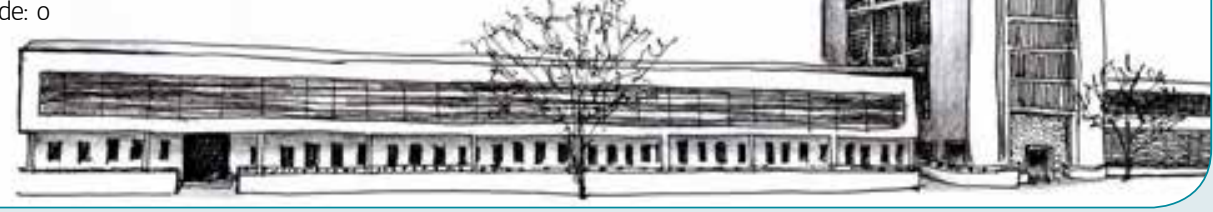

\section{LIBERDADE}

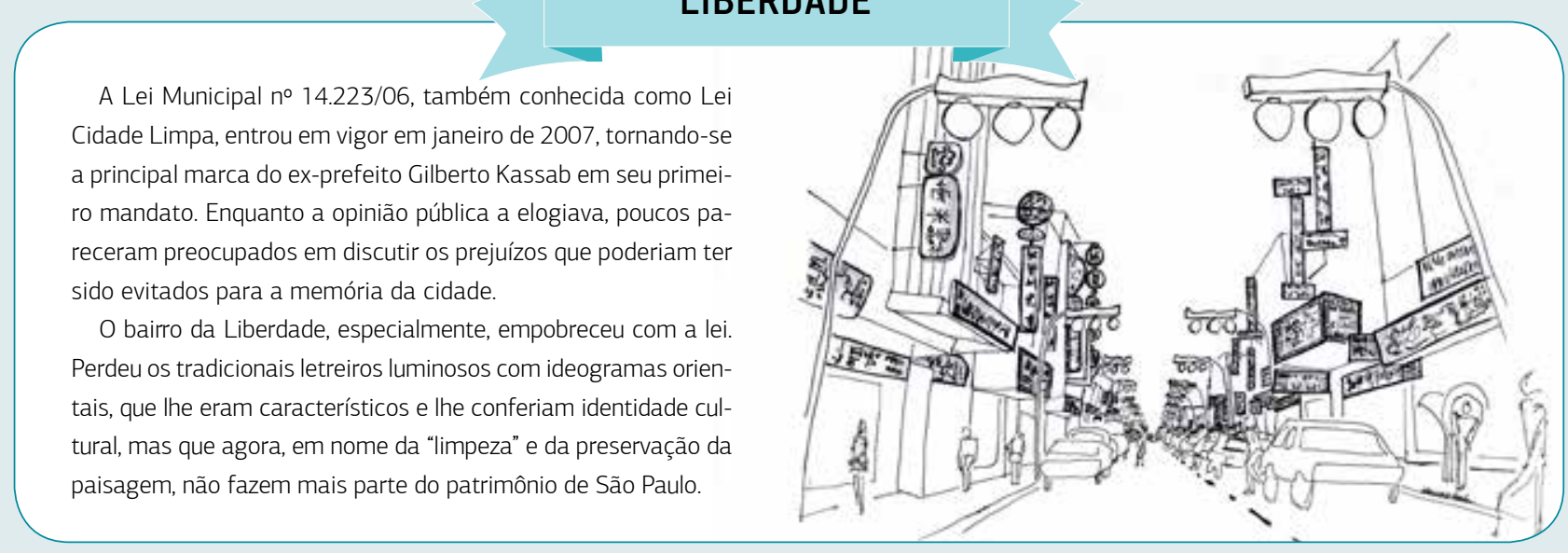

PARA SABER MAIS:

- História e memória. Jacques Le Goff. 1990.

- São Paulo: três cidades em um século. Benedito Lima de Toledo. 2004

- Quando a cidade era mais gentil. Martin Jayo. Disponivel em: www.quandoacidade.wordpress.com

MARTIN JAYO > Professor da Escola de Artes, Ciências e Humanidades da Universidade de São Paulo (EACH-USP) > martin.jayo@usp.br 